\title{
Mexican Higher Education in Transition: From Politically to Financially Driven Public Policies
}

\section{Imanol Ordorika}

Imanol Ordorika is on the faculty of the National Autonomous University of Mexico, Merxico City. He is currently completing work on a doctoral degree in the School of Education, Stanford Univeresity, Stanford CA 94305.

T he higher education system in Mexico has undergone a long process of transition since 1982. This transition is the consequence of major shifts in state policy toward higher education. In very broad terms it is possible to say that public policies have changed from politically driven concerns, mainly addressing issues of equity, to financially driven concerns, mainly addressing issues of efficiency.

In this article I will look at this transition in terms of changes in enrollment and funding policies. I will also address other efficiency measures that have been pressed upon higher education institutions and their consequences for academic life.

State policies toward higher education in Mexico, in the 1970s and early 1980s, can be explained to a great extent, by the government's need to overcome the open breech with the urban middle classes and intellectuals, a consequence of the violent response to the 1968 student movement. Government higher education policies were shaped, until 1982, by a strong belief in the impact of university and technological education on national development, and by the need to recover state legitimacy by expanding opportunities for social mobility through higher education.

The worldwide massification process in the 1960s and early 1970s was exacerbated, in the Mexican case, by state policies that focused mainly on increasing enrollments. Public policies during this period can be characterized by the massification of public institutions, rapidly increasing flow of resources, and concerns about political control. Enrollment growth and these concerns about political control over public universities generated a large expansion of university bureaucracies.

The heavy reliance on the oil trade in the Mexican economy and the increase in the foreign debt generated a new economic crisis in 1982. The International Monetary Fund (IMF) put forward a "rescue package" with a corresponding stabilization plan for the Mexican economy. The conditions imposed by the IMF upon the Mexican policies were: reorganization of public finances, control of inflation, reduction of public expenditure, and guaranteed for- eign debt payment.

The era of politically driven public policies toward higher education was over. The economic crisis and structural adjustment policies reduced the flow of financial resources for public higher education. New government policies on public expenditure generated strong shifts in views about public higher education.

The concern with expansion and coverage was replaced by concern for quality and efficiency. Enrollment rates decreased after 1982. Public and private perceptions about postsecondary education also changed. Public higher education institutions were the subject of widespread criticism and contempt. A new era of financially driven policies started.

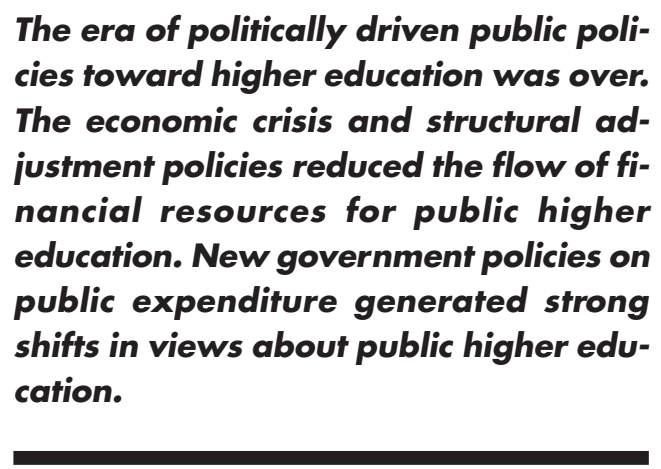

New state policies toward higher education have stressed the importance of efficiency and accountabilty in postsecondary institutions. The diversification of the system, the building of alternative financial sources, cuts in spending, concerns about productivity and the establishment of multiple levels of evaluation have been the major issues affecting higher education. Progress in these areas has been uneven.

Government policies promoted institutional diversity. Many university/technological institutions were created after 1982. Institutional differentiation, however, was not complete. Many technological schools look like universities. This is still the case with the National Polytechnic Institute (IPN), the head of the technological subsystem. These institutions have received less funding than equivalent organizations in the university subsystem. In spite of diversification attempts 75 percent of students still demand 
access to universities in what the government has called "distorted student demand."

Public universities still rely mainly on public financing. Internal budgetary cuts have concentrated on tremendous faculty and staff salary reductions, with damaging effects on academic performance. Diverse universities and entire disciplines have been regarded as unproductive while the notion of productivity in higher education is still ambiguous and ill-defined.

Evaluation has been presented as the most important policy device. Different evaluation processes range from the most general institutional evaluation, to school, faculty- and department-based evaluation, and even at the individual level (students and faculty). Institutional evaluation will allegedly guide public funding allocation. School, faculty, and department evaluations will guide institutional strategies and internal allocation. Finally, faculty evaluation guides salary compensation and access to "competition monies."

Evaluation processes and rules have been designed in haste, with inadequate analysis, and disregarding previous experiences. Among the most important unintended effects of academic evaluation we can identify:

1. a high consideration for research and low regard for teaching that is escalating the growing imbalance between these activities. This process is already affecting preparatory and undergraduate education and faculty members at the mentioned teaching levels.

2. enhanced disparity between the hard sciences and social and humanistic disciplines through the adoption of evaluation methods designed by and for the hard sciences.

3. accumulation of administrative responsabilities for faculty who are subject to diverse to multiple evaluations in their quest for higher status and financial resources.

4. shift from long-range deeply inquisitive research to short-term inquiry rendering faster results and therefore higher evaluation scores.

While higher education started a slow financial recovery after 1990, new external demands, evaluation policies, and low faculty salaries have continued to affect academic performance. A thorough analysis of the effects of these processes on the quality and scope of research and teaching has yet to be produced. Negative effects are now visible, but financially driven policies and reforms are still in place and have not been the object of thorough evaluation.
The transition from a higher education system that was driven by external political demands and concerns to one that responds to financial stimulus and demands is not necesarily positive. This transition has not improved many of the predicaments affecting Mexican higher education.

Bloated politicized bureaucracies still control most public institutions. Resources are scarce. Enrollment levels are increasingly insufficient. Faculty are demoralized and teaching has been downgraded. Higher education is heavily centralized and institutions receive unequal treatment. In many cases the curriculum is old and has little relevance. Student financial aid is almost nonexistent.

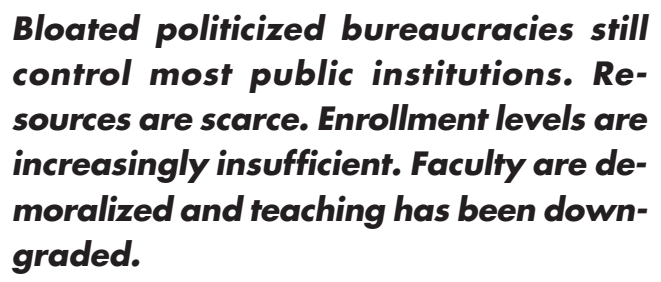

This is a small sample of the many problems that affect higher education in Mexico. There is a general consensus on the need for reform of postsecondary education. For the first time in many years, reform processes could be driven by academic concerns. Political demands and financial constraints must obviously be taken into consideration in the development of new academically driven policies. Faculty and students must assume their role in the analysis of higher education institutions and the development of new programs and initiatives. Academic considerations must now play a major role for once in public policy formation regarding higher education institutions. 